\title{
Solubility and Segregation of Co in CdTe-Based Ternary and Quaternary Alloys
}

\author{
S. Miotkowska ${ }^{a}$, E. Dynowska $^{a}$, I. Miothowski $^{b, *}$, \\ H. Alawadhi ${ }^{c}$, A. LeWICKI ${ }^{b}$, P.A. MetcalF ${ }^{b}$ \\ AND A.K. RAMDAS ${ }^{b}$ \\ ${ }^{a}$ Institute of Physics, Polish Academy of Sciences \\ al. Lotników 32/46, 02-668 Warsaw, Poland \\ ${ }^{b}$ Department of Physics, Purdue University, West Lafayette, IN 47907, USA \\ ${ }^{c}$ Department of Basic Sciences, University of Sharjah, United Arab Emirates \\ Single crystals of $\mathrm{Cd}_{1-x} \mathrm{Co}_{x} \mathrm{Te}$ and $\mathrm{Cd}_{1-x-y} \mathrm{Co}_{x} \mathrm{Mn}_{y} \mathrm{Te}$ are character- \\ ized with X-ray powder diffraction and electron microprobe to establish com- \\ positional dependence of the lattice parameters and deduce Co solubility \\ limit. The experimental compositional profiles are examined on specimens \\ taken from various locations of ingots along their longitudinal axes and com- \\ pared with normal freezing distributions. The values of Co segregation coeffi- \\ cient are analyzed for both ternary and quaternary alloys in terms of normal \\ freezing mode.
}

PACS numbers: 81.05.Dz, 81.10.-h

\section{Introduction}

Among diluted magnetic semiconductors (DMSs), Co-based II-VI alloys are of special interest due to the strong interaction between the $\mathrm{Co}^{2+}$ ions [1-3] and the large effective Lande $g$-factor of $\mathrm{Co}^{2+}$ in the host lattice [4]. As a consequence, compared to other DMSs, Co-based compounds are expected to show magnetic ordering related phenomena at higher temperatures [5]. To date, most of the studies on Co-based II-VI DMSs have been carried out on the sulphides and selenides

*corresponding author; e-mail: irek@physics.purdue.edu 
[6-8]. One of the critical parameters limiting the availability of Co-based tellurides is the low solubility of Co in the zinc-blende structure of II-VI compounds [9-11]. Therefore, our effort has been focused on preparation of homogeneous and inclusion-free alloys using optimal stoichiometry control and cooling conditions during the crystal growth.

We have recently reported estimates of the Co solubility in CdTe using high temperature magnetic susceptibility analysis and spectroscopic measurements [12]. In this paper we present a more detailed study of Co solubility in the quaternary $\mathrm{Cd}_{1-x-y} \mathrm{Co}_{x} \mathrm{Mn}_{y}$ Te alloys as obtained from X-ray and electron microprobe characterization. Cross-sectional microprobe data are also used for detailed description of the Co segregation in both $\mathrm{Cd}_{1-x} \mathrm{Co}_{x} \mathrm{Te}$ and $\mathrm{Cd}_{1-x-y} \mathrm{Co}_{x} \mathrm{Mn}_{y} \mathrm{Te}$.

\section{Experimental}

The ternary $\mathrm{Cd}_{1-x} \mathrm{Co}_{x}$ Te and quaternary $\mathrm{Cd}_{1-x-y} \mathrm{Co}_{x} \mathrm{Mn}_{y}$ Te crystals were grown by the vertical Bridgman technique. The compositions of the samples were determined using a JEOL JXA-6400 scanning electron microscope with a LINK system for energy dispersive electron microprobe analysis (ED EMPA). Due to the relatively low Co concentrations, $x$, additional microprobe measurements were also carried out with a CAMECA SX-50 electron microprobe analyzer. The quantitative EMPA results were obtained using high-quality single crystals of CdTe and pure $\mathrm{Co}$ as standards. The accuracy in the composition determination is estimated to be about 0.1 at\%. The X-ray powder diffraction (XRD) measurements were performed with an automated diffractometer on samples cut from the middle part of ingots. The lattice parameter was obtained from reflections measured up to $2 \Theta=140^{\circ}$ using the Nelson-Riley extrapolation method. The wavelength-modulated reflectivity (WMR) measurements were carried out in a Janis cryostat at $5 \mathrm{~K}$ with a SPEX monochromator. A full description of the procedure used is given in Ref. [12].

\section{Results and discussion}

As revealed by X-ray powder diffraction, the $\mathrm{Cd}_{1-x} \mathrm{Co}_{x} \mathrm{Te}$ and $\mathrm{Cd}_{1-x-y} \mathrm{Co}_{x} \mathrm{Mn}_{y}$ Te single crystals retain the zinc-blende structure of CdTe for the entire range of $\mathrm{Co}$ concentrations studied. As shown in Fig. 1, the lattice parameter, $a$, decreases with increasing concentration of Co due to the smaller tetrahedral radii of $\mathrm{Co}\left(r_{\mathrm{Co}}=0.1202 \mathrm{~nm}[12,13]\right)$ and $\mathrm{Mn}\left(r_{\mathrm{Mn}}=0.1326 \mathrm{~nm}\right.$ [14]), both substituting for $\mathrm{Cd}\left(r_{\mathrm{Cd}}=0.1405 \mathrm{~nm}\right.$ [15]) in the zinc-blende structure of CdTe. The concentration dependence of $a$ can be described by the linear equation

$$
a(x, y)=0.64813-0.0387 x-0.0181 y \mathrm{~nm},
$$


as obtained from the best fit of all the experimental data. We note here that the coefficients in the linear Eq. (1) agree well with those reported for both $\mathrm{Cd}_{1-x} \mathrm{Co}_{x} \mathrm{Te}\left(0.04020\right.$ [12]) and $\mathrm{Cd}_{1-y} \mathrm{Mn}_{y} \mathrm{Te}(0.0151$ [16]) bulk crystals. The MnTe lattice parameter of $0.6300 \mathrm{~nm}$ extracted from Eq. (1) differs by $0.58 \%$ if compared to the experimental value measured on MBE-grown zinc-blende material $\left(a_{\mathrm{MnTe}}^{\mathrm{MBE}}=0.6337 \mathrm{~nm}[17]\right)$ and by $0.53 \%$ from that of $0.6334 \mathrm{~nm}$ reported by Furdyna et al. [18]. These discrepancies are most likely related to the limited region of Mn concentrations $(y \leq 0.20)$ used in this study.

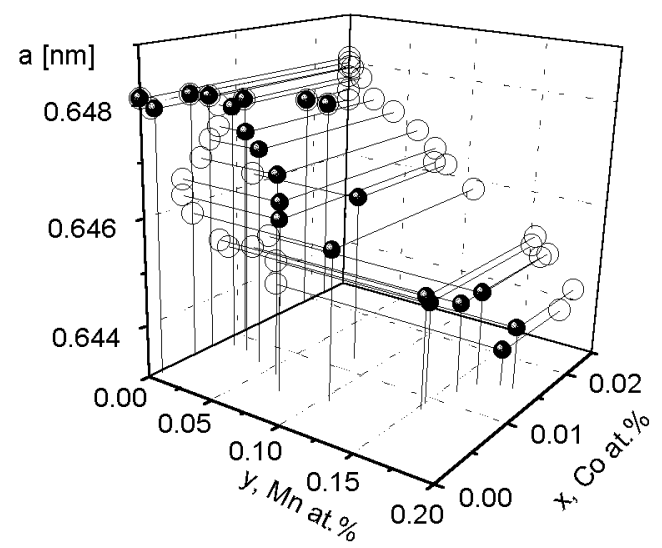

Fig. 1. Composition dependence of the lattice parameters for $\mathrm{Cd}_{1-x-y} \mathrm{Co}_{x} \mathrm{Mn}_{y} \mathrm{Te}$ alloys. Solid circles show a values, open circles represent their $X Z$ and $Y Z$ projections. Double symbols $(\odot)$ indicate $a$ values for ternary $\mathrm{Cd}_{1-x} \mathrm{Co}_{x} \mathrm{Te}$ alloys.

It is also observed that the lattice parameters obey Vegard's law within the relatively low (as compared with $\mathrm{Mn}$ ) range of Co concentrations with the maximum value $x=0.022$ obtained for $y=0$. All the microprobe and X-ray data clearly indicate that the solubility of Co in zinc-blende CdTe matrix is slightly reduced to about $x=0.015$ in the presence of $\mathrm{Mn}$ for the range of $0.10<y \leq 0.185$. We also note that all the samples described here showed radial compositional variations of $\Delta x \leq 0.003$. These variations are most likely attributed to changes in the liquid-solid interface caused by thermal instabilities during the growth process.

It should be noted here that an estimate of Co solubility limit in ternary alloys has already been confirmed independently of X-ray, magnetic susceptibility and spectroscopic measurements [12]. For quaternary alloys, a similar approach could not be fully applied due to difficulties in separating the additional contributions from interactions between $\mathrm{Co}^{2+}$ and $\mathrm{Mn}^{2+}$ ions. However, the WMR spectra clearly indicate that the free exciton position for $\mathrm{Cd}_{1-x-y} \mathrm{Co}_{x} \mathrm{Mn}_{y} \mathrm{Te}$ undergoes a higher blue shift compared to what is expected for $\mathrm{Cd}_{1-y} \mathrm{Mn}_{y} \mathrm{Te}$ alone with the same Mn concentration. As an example, in Fig. 2 we show the WMR spectrum of a $\mathrm{Cd}_{0.78} \mathrm{Co}_{0.02} \mathrm{Mn}_{0.20} \mathrm{Te}$ sample, where the free exciton signature is 
shifted $354 \mathrm{meV}$ compared to that of pure CdTe. For $\mathrm{Cd}_{1-y} \mathrm{Mn}_{y} \mathrm{Te}$, a shift of only $320 \mathrm{meV}$ is expected for $y=0.20$ [19]. Thus, the additional excitonic shift of $34 \mathrm{meV}$ can be attributed to the substitutional Co, in agreement with data reported for $\mathrm{Cd}_{1-x} \mathrm{Co}_{x} \mathrm{Te}$ alloys [20].

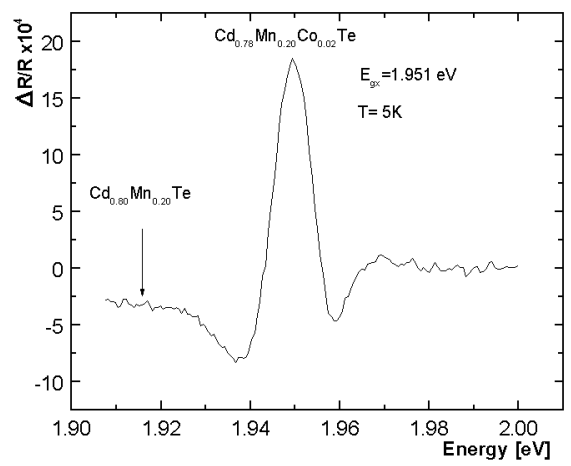

Fig. 2. Wavelength-modulated reflectivity spectrum of $\mathrm{Cd}_{0.78} \mathrm{Co}_{0.02} \mathrm{Mn}_{0.20} \mathrm{Te}$ at $5 \mathrm{~K}$. An arrow indicates a position of the free excitonic signature for $\mathrm{Cd}_{0.80} \mathrm{Mn}_{0.20} \mathrm{Te}$.

It is also observed that for both $\mathrm{Cd}_{1-x} \mathrm{Co}_{x} \mathrm{Te}$ and $\mathrm{Cd}_{1-x-y} \mathrm{Co}_{x} \mathrm{Mn}_{y}$ Te the alloys become inhomogeneous as the concentration of Co increases over the solubility limits. They either contain small amounts of CoTe (with a NiAs structure) in the CdTe-rich matrix of $\mathrm{Cd}_{1-x} \mathrm{Co}_{x} \mathrm{Te}$ and/or unreacted $\mathrm{Co}$ in $\mathrm{Cd}_{1-x-y} \mathrm{Co}_{x} \mathrm{Mn}_{y} \mathrm{Te}$.

Figure 3 shows a distribution of $\mathrm{Co}$ in the $\mathrm{Cd}_{1-x} \mathrm{Co}_{x}$ Te crystals obtained from microprobe examinations on slices cut from various ingot locations along the longitudinal axis. For both nominal concentrations, $x_{0}=0.01$ and 0.02 in
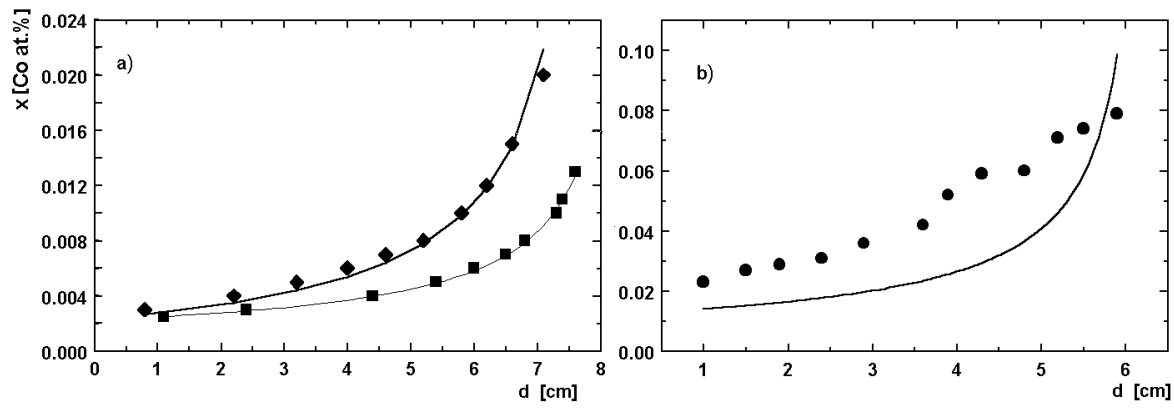

Fig. 3. Distribution of $\mathrm{Co}$ along the longitudinal axis in $\mathrm{Cd}_{1-x} \mathrm{Co}_{x} \mathrm{Te}$ alloys: (a) full diamond $x_{0}=0.01$, $x_{0}=0.02$, (b) $\bullet x_{0}=0.05$. The solid lines show distributions fitted to the experimental data using the Pfann equation: $k_{\mathrm{Co}_{0}}=0.227$ for $x_{0}=0.01$ and 0.239 for $x_{0}=0.02$, respectively. The solid line for $x_{0}=0.05$ was calculated with an average $k_{\mathrm{Co}}$ value of 0.23 . The value of $d=0$ corresponds to the first-to-freeze region of crystal. 
Fig. 3a, the actual Co concentration increases with increasing distance $d$ from the first-to-freeze region.

It is well known that the compositional profile, in mixed crystals such as $\mathrm{CdTe}-\mathrm{CoTe}$ and/or CdTe-MnTe-CoTe grown under equilibrium conditions, is expected to change monotonically with proceeding solidification of the melt. The actual shape of the compositional profile depends on the controlling mechanisms: diffusion and convection in the melt. The Pfann equation [21]:

$$
x_{i}(d)=k x_{0}\left(1-\frac{d}{L}\right)^{k-1}
$$

describes variations of the crystal composition $x_{i}(d)$ as a function of distance $d$ from the first-to-freeze position along the longitudinal axis of the crystal $L$, assuming a complete mixing of the component rejected at the advancing melt-crystal interface. In a crystal with an initial concentration $x_{0}$, the actual concentration at the first-to-freeze region is expected to be $x_{i}(0)=k x_{0}$, where $k$ denotes a segregation coefficient. At the other extreme case, assuming that mixing of the melt is controlled by diffusion, the Tiller equation [22]:

$$
x_{i}(d)=x_{0}\left[1-(1-k) \exp \left(-k R D^{-1} d\right)\right]
$$

can be applied to calculate the distribution profile. In Eq. (3), $R$ is the crystal growth rate and $D$ represents the diffusion coefficient in the melt.

The relatively steep experimental profile in Fig. 3 a indicates a complete mixing in the melt, with convection as the primary (and dominant) transport mechanism. In order to extract the segregation coefficient value $k_{\mathrm{Co}}$, our experimental data were fitted to Eq. (2). The best fitting of the Pfann equation (solid lines in Fig. 3a) is obtained with $k_{\mathrm{Co}_{0}}=0.227$ and 0.239 for $x_{0}=0.01$ and 0.02 , respectively. Both values extracted here are much higher than values of 0.11 and 0.16 reported in Refs. [23, 24], but agree relatively well with the value of 0.27 obtained in Ref. [25] and that of 0.3 in Ref. [26].

For comparison, in Fig. $3 \mathrm{~b}$ we show the distribution of $\mathrm{Co}$ in the $\mathrm{Cd}_{1-x} \mathrm{Co}_{x} \mathrm{Te}$ ingot with a nominal concentration of $x_{0}=0.05$. In contrast to the ingots with nominal concentrations below the solubility limit, the experimental distribution of Fig. 3b could not be fitted by Eq. (2). The actual Co distribution is not as steep as one would expect for an equilibrium distribution calculated for $x_{0}=0.05$ with $k_{\text {Co }}=0.23$ (solid line in Fig. 3b), and confirms the heterogeneous nature of the ingot, as was described earlier.

If two solutes (i.e., MnTe and CoTe) are present in a melt simultaneously, it may be assumed that they will behave independently [27]. Thus, in order to obtain the segregation coefficient, the Pfann equation may be applied to each component by fitting its experimental distribution individually. In Fig. 4, we show both the distribution of Co and that of $\mathrm{Mn}$ along the longitudinal axis of $\mathrm{C}_{1-x-y} \mathrm{Co}_{x} \mathrm{Mn}_{y} \mathrm{Te}$ single crystal with nominal concentrations $x_{0}=0.02$ and $y_{0}=0.20$. It should be noted that, while the compositional profile of Co remains essentially unchanged as 
compared with the one shown in Fig. 3a for a ternary alloy with the same nominal concentration of $x_{0}=0.02$, the Mn concentration decreases along the crystal, indicating that $k_{\mathrm{Mn}}>1$. Indeed, from the $\mathrm{Mn}$ distribution profile, $k_{\mathrm{Mn}}=1.06$ is obtained as the best fit using Eq. (2). Similarly, $k_{\mathrm{Co}}=0.260$ is extracted for Co, which corresponds well to the values for $\mathrm{Cd}_{1-x} \mathrm{Co}_{x} \mathrm{Te}$, as described above.
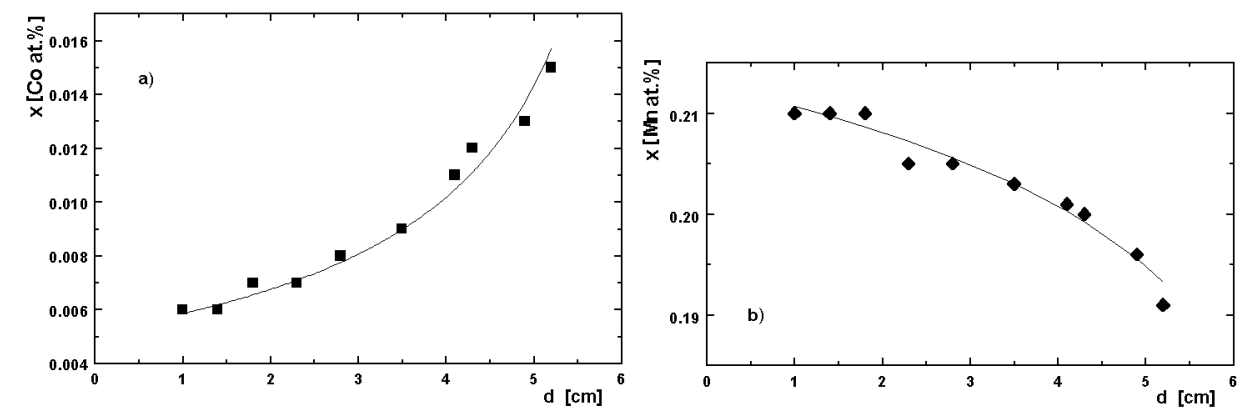

Fig. 4. Distributions of Co ( $\mathbf{m})$ and Mn (full diamond) along the longitudinal axis of $\mathrm{Cd}_{1-x-y} \mathrm{Co}_{x} \mathrm{Mn}_{y} \mathrm{Te}$ crystal with a nominal composition $x_{0}=0.02$ and $y_{0}=0.20$. The solid lines are best fits obtained from the Pfann equation: $k_{\mathrm{Co}}=0.26$ and $k_{\mathrm{Mn}}=1.06$.

The data reported by others [14, 28] on pseudobinary CdTe-MnTe system do not implicate any significant segregation of Mn during the solidification process, because of the unique coincidence of the liquidus and solidus lines on the phase diagram. For that reason, the compositions of the melt-grown single crystals of $\mathrm{Cd}_{1-y} \mathrm{Mn}_{y}$ Te are considered "close to the nominal value" (i.e., $k_{\mathrm{Mn}}=1$ ) [14], at least for lower Mn contents. Since no accurate data on the distribution of Mn are a vailable, any analysis of possible impact of Co on the distribution of Mn must be taken cautiously. In fact, in the first-to-freeze part of the ingot shown in Fig. 4, the Mn concentration remains constant for low concentrations of incorporated Co. Since the measured value of $\mathrm{Mn}$ concentration is only slightly higher than its initial concentration of $y_{0}=0.20$, it may well be assumed to be independent of Co concentration. However, further decrease in Mn concentration observed with increasing concentration of Co in the growing crystal may suggest some influence of the latter on the distribution of the former. Since the overall changes of $\mathrm{Mn}$ concentration are rather small and do not exceed a range of 0.02 along the entire ingot, more detailed studies are necessary to distinguish and/or separate the effect of Co on Mn distribution from a segregation of Mn itself.

\section{Concluding remarks}

X-ray and microprobe analysis has shown the possibility of growing homogeneous and inclusion-free, Co-based ternary and quaternary tellurides with extended regions of cobalt content. Co-based tellurides appear to be difficult to grow 
with concentrations above $x=0.022$ due to their tendency towards formation of the hexagonal NiAs structure rather than substitutional incorporation of Co atoms into the zinc-blende structure of the host. In spite of the unfavorable value of the segregation coefficient $\left(k_{\mathrm{Co}}<1\right)$, a better understanding of segregation phenomena offers the realization and control of some of the properties that become a vailable for these alloys.

\section{Acknowledgments}

The authors are indebted to C. Hager for his skillful assistance in some of the microprobe examinations. The present investigation received support from the US National Science Foundation, grants No. DMR 0102699 and ECS-0129853. The financial support by Purdue University through the University Reinvestment Program is gratefully appreciated.

\section{References}

[1] W.J.M. de Jonge, H.J.M. Swagten, J. Magn. Magn. Mater. 100, 322 (1991).

[2] P. Kacman, Semicond. Sci. Technol. 16, R25 (2001).

[3] H. Alawadhi, I. Miotkowski, V. Souw, M. McElfresh, A.K. Ramdas, S. Miotkowska, Phys. Rev. B 63, 155201 (2001).

[4] M.J. Seong, H. Alawadhi, I. Miotkowski, A.K. Ramdas, S. Miotkowska, Phys. Rev. $B$ 63, 125208 (2001).

[5] D. Heiman, in: 12th Int. Conf. on High Fields in the Physics of Semiconductors, Ed. G. Landwehr, W. Ossau, World Scientific, Singapore 1997, p. 847.

[6] T.M. Giebultowicz, P. Klosowski, J.J. Rhyne, T.J. Udovic, J.K. Furdyna, W. Giriat, Phys. Rev. B 41, 504 (1990).

[7] A. Lewicki, A.I. Schindler, J.K. Furdyna, W. Giriat, Phys. Rev. B 40, 2379 (1989).

[8] A. Lewicki, A.I. Schindler, I. Miotkowski, J.K. Furdyna, Phys. Rev. B 41, 4653 (1990)

[9] O.W. Shih, R.L. Aggarwal, T.Q. Vu, P. Becla, Solid State Commun. 81, 245 (1992).

[10] D. Coquillat, Yu.G. Rubo, A. El Quazzani, A. Ribavol, J.P. Lascaray, R. Triboulet, in: II-VI Compounds and Semimagnetic Semiconductors, Materials Science Forum, Vols. 182-184, Eds. H. Heinrich, J.B. Mullin, Trans Tech Publications, Switzerland 1995, p. 503.

[11] M. Zielinski, C. Rigaux, A. Mycielski, M. Menant, Phys. Rev. B 63, 035202 (2001).

[12] I. Miotkowski, H. Alawadhi, M.J. Seong, A. Lewicki, V. Souw, M. McElfresh, A.K. Ramdas, S. Miotkowska, E. Dynowska, Semicond. Sci. Technol. 16, 118 (2001).

[13] R. Iwanowski, K. Lawniczak-Jablonska, Z. Golacki, A. Traverse, Chem. Phys. Lett. 283, 313 (1998). 
[14] W. Giriat, J.K. Furdyna, in: Diluted Magnetic Semiconductors, Semiconductors and Semimetals, Vol. 25, Ed. R.K. Willardson, A.C. Beer, Academic Press, San Diego 1988, p. 1.

[15] J.A. Van Vechten, J.C. Phillips, Phys. Rev. B 2, 2160 (1970).

[16] S. Miotkowska, E. Dynowska, I. Miotkowski, Acta Phys. Pol. A 86, 605 (1994).

[17] E. Janik, E. Dynowska, J. Bak-Misiuk, M. Leszczynski, W. Szuszkiewicz, T. Wojtowicz, G. Karczewski, A.K. Zakrzewski, J. Kossut, Thin Solid Films 267, $74(1995)$

[18] J.K. Furdyna, W. Giriat, D.F. Mitchell, G. Spoule, J. Solid State Chem. 46, 349 (1983).

[19] Y.R. Lee, A.K. Ramdas, R.L. Aggarwal, Phys.Rev. B 38, 10600 (1988).

[20] H. Alawadhi, I. Miotkowski, A. Lewicki, A.K. Ramdas, S. Miotkowska, submitted to Semicond. Sci. Technol.

[21] W.G. Pfann, Zone Melting, Wiley, New York 1966.

[22] W.A. Tiller, K.A. Jackson, J.W. Rutter, B. Chalmers, Acta Metallurg. 1, 428 (1953)

[23] L. Kuchar, J. Drapala, J. Lunacek, J. Cryst. Growth 161, 94 (1996).

[24] A.V. Vannyukov, J.M. Ivanov, A.V. Namn, N.G. Sedelnikov, B.S. Krasulina, O.F. Kravchenko, Elektron. Tekh., Ser. Materialy 6, 72 (1976).

[25] H.H. Woodbury, R.S. Lewandowski, J. Cryst. Growth 10, 6 (1971).

[26] M. Isshiki, M. Sato, K. Masumoto, J. Cryst. Growth 78, 58 (1986).

[27] V.G. Smith, W.A. Tiller, J.W. Rutter, Can. J. Phys. 33, 723 (1955).

[28] R. Triboulet, G. Didier, J. Cryst. Growth 52, 614 (1981). 